\title{
Cognitive performance of people with traumatic spinal cord injury: a cross-sectional study comparing people with subacute and chronic injuries
}

\author{
B. Molina ${ }^{1,2} \cdot$ A. Segura ${ }^{3} \cdot$ J.P. Serrano ${ }^{4} \cdot$ F.J. Alonso $^{5} \cdot$ L. Molina $^{6} \cdot$ Y.A. Pérez-Borrego $^{1} \cdot$ M.I. Ugarte $^{7} \cdot$ A. Oliviero $^{1}$
}

Received: 12 July 2017 / Revised: 26 January 2018 / Accepted: 28 January 2018 / Published online: 22 February 2018

(c) International Spinal Cord Society 2018

\begin{abstract}
Study design Cross-sectional study.

Objectives To assess the impact of spinal cord injury (SCI) on cognitive function in individuals with subacute and chronic SCI.

Setting National Hospital for SCI patients (Spain).

Methods The present investigation was designed to determine the nature, pattern, and extent of cognitive deficits in a group of participants with subacute $(n=32)$ and chronic $(n=34)$ SCI, using a comprehensive battery of reliable and validated neuropsychological assessments to study a broad range of cognitive functions. Twenty-seven able-bodied subjects matched to the groups with SCI for age and educational level formed the control group.

Results The neuropsychological assessment showed alterations in the domain of attention, processing speed, memory and learning, executive functions, and in recognition in participants with SCI. The prevalence of cognitive dysfunction in the chronic stage was also confirmed at the individual level. The comparison of the neuropsychological assessment between the groups with subacute and chronic SCI showed a worsening of cognitive functions in those with chronic SCI compared to the group with subacute SCI.

Conclusions In participants with SCI, cognitive dysfunctions are present in the subacute stage and worsen over time. From a clinical point of view, we confirmed the presence of cognitive dysfunction that may interfere with the first stage of rehabilitation which is the most intense and important. Moreover, cognitive dysfunction may be important beyond the end of the first stage of rehabilitation as it can affect an individual's quality of life and possible integration to society.
\end{abstract}

A. Oliviero

antonioo@ sescam.jccm.es

1 FENNSI Group, Hospital Nacional de Parapléjicos, SESCAM, Toledo, Spain

2 Nursing Department, Hospital Nacional de Parapléjicos, SESCAM, Toledo, Spain

3 Health Science Institute, Department of Health and Social Affairs, Castilla-La Mancha Government, Talavera de la Reina, Spain

4 Faculty of Medicine, Department of Psychology, University of Castilla-la Mancha, Albacete, Spain

5 Department for Primary Health Care, Centro de Salud Sillería, Toledo, Spain

6 Nursing Department, Hospital Mancha-Centro. SESCAM, Álcazar de San Juan, Ciudad Real, Spain

7 Nursing Department, University of Castilla-la Mancha, Toledo, Spain

\section{Introduction}

Spinal cord injury (SCI) occurs when the spinal cord is severely bruised, compressed, lacerated, or severed as a result of traumatic injury or disease. SCI is associated with the development of secondary conditions such as chronic pain, infections, and chronic fatigue, all of which contribute to lowered quality of life and potentially reduced social participation [1-4].

Furthermore, cognitive impairment is highly prevalent in the population with SCI [5-12], being reported in as much as $60 \%$ of individuals [6]. Commonly reported cognitive deficits include poor attention and concentration, disturbed memory and learning, impaired visuospatial perception, and decreased problem solving ability [5, 9, 11].

Comorbid traumatic brain injury (TBI) is a common cause of cognitive impairment in people with SCI [5, 8, 10,], and this is problematic, as TBI in these individuals is most likely 
underdiagnosed $[5,10$,$] . Factors other than the presence of a$ TBI also contribute to cognitive impairment in those with SCI, and these include pre-injury learning difficulties and/or head trauma, fatigue, chronic pain, taking multiple medications, alcohol and substance abuse, and older age [5, 8-13]. Furthermore, studies have generally failed to investigate for the presence of depression, which has also been linked with reduced cognitive performance [14].

Elevated levels of depressive mood states have been found in people with chronic SCI, with rates ranging between $19 \%$ and $30 \%$ [13, 15-17]; whereas alcohol and drug abuse is estimated to be prevalent in up to $16 \%$ of those with SCI [13]. However, Davidoff and colleagues showed that neuropsychological performance was weakly related to depressive mood, although they only assessed depressive mood once using a cross-sectional design 8 weeks after the injury.

Recently, it has been reported that the risk of an adult with SCI having cognitive impairment is nearly 13 times higher than that of someone without a SCI [18]. Moreover, the development of negative mood states was a significant problem in those patients with cognitive impairment after the first rehabilitation period [18].

A major aim of the present study was to determine the rates of cognitive impairment in a sample of people with subacute SCI, with comparisons to those with chronic SCI. The main objectives of the present study were to determine if participants with subacute SCI showed cognitive deficits on a neuropsychological battery when compared to participants with chronic SCI, who were matched for critical demographic factors. We were particularly interested in whether those with chronic SCI would show evidence of impairment or improvement in different areas of cognitive function. We performed a parallel study passing the same neuropsychological battery in two different samples of individuals with traumatic SCI.

Although some neuropsychological deficits may be transient, many problems may persist during or beyond the first few months following injury. Recognition of the presence of these cognitive deficits during the initial rehabilitation stage is important because this is the time period during which intensive rehabilitation takes place. Rehabilitation of the patient with SCI is an intensive process that includes training in personal care, mobility, and community skills and the facilitation of physical and psychosocial adaptation to the disability; any impediment to learning and adjustment that these cognitive problems may pose could compromise the achievement of optimal rehabilitation outcomes. Moreover, cognitive deficits in the chronic stage may interfere with peoples' capacity to achieve optimal social reintroduction. Most of the studies on the cognitive functions in people with SCI have been limited to the subacute stage (a few months after the injury). Cognitive dysfunction after SCI might be progressive due to several factors such as the cumulative effects of neuroactive drugs, brain inflammation, psychological factors, etc [18-20].

The present investigation was designed to:

1. Determine the nature, pattern, and extent of cognitive deficits in a group of participants with subacute or chronic SCI using a comprehensive battery of reliable and validated neuropsychological assessments to study a broad range of cognitive functions.

2. Compare the cognitive deficits present in the subacute stage of SCI with those seen in the chronic stage matched for age, sex, and educational level.

Our "a priori" hypothesis is that some cognitive deficits directly or indirectly caused by the SCI may improve with time, others can be stable over time, and others could worsen (or develop) in the chronic stage. From a clinical point of view, it is important to detect the presence of cognitive dysfunction as it may interfere with the first stage of the rehabilitation that is the most intense and important one. Moreover, cognitive impairment can affect an individual's quality of life and the possible full integration to society.

\section{Methods}

\section{Participants}

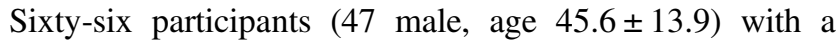
traumatic SCI of whom 32 were included in the subacute stage group ( 23 male, age $44.4 \pm 15.7$ ) and 34 were inclu-

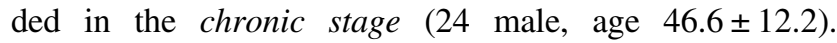
Twenty-seven able-bodied subjects matched to the groups with SCI for age and educational level formed the control group (12 male, age $44.9 \pm 15.5$ ). In the subacute stage, we included participants with a recent first-time admission to our SCI unit with a time from injury ranging from 4 to 6 months. In the chronic stage, we included participants with a time from injury of at least 1 year that were attending the hospital for normal annual follow-up. The participants with SCI were recruited from the "National Hospital for Paraplegics" a SCI rehabilitation hospital. The individuals with subacute stage were recruited when admitted to the hospital for rehabilitation. The group with chronic SCI was recruited from individuals who were attending the hospital for annual follow-up. Able-bodied participants were recruited randomly among people working at the hospital or who were relatives of those with SCI.

Inclusion criteria for both groups consisted of (1) the presence of traumatic SCI; (2) injury level below C4; (3) age at injury 18 years or older; (4) age $18-85$ years at the time of interview; (5) Spanish speaking; (6) score at the mini-mental state exam (MMSE) of 22 or more (see neuropsychological assessment). 
Exclusion criteria included: (1) no radiological evidence of SCI; (2) lesion level above C4; (3) age of injury younger than 18 years (e.g., SCI during the childhood or adolescence); (4) the presence of clinically demonstrated TBI (due to the known association of TBI with cognitive dysfunction); (5) severe psychiatric disorders; (6) history of central or peripheral neurological problems prior to the SCI; (7) known history of alcohol and drug abuse.

The study was approved by the local ethical committee. Written informed consent was obtained for all subjects prior to their participation in the study.

\section{Study design}

This is a cross-sectional study comparing participants with SCI in the subacute and chronic stages matched for age, sex, and educational level (case control study design). Moreover, we compared both groups with a control group without SCI.

\section{Clinical and demographic data}

Demographic information was collected from each participant including: age, sex, education (read/write, primary school, secondary school, and university). Moreover, each participant was questioned regarding a history of high frequency alcohol and/or substance use [21, 22,].

Clinical information included: lesion level (cervical, dorsal, and lumbar), American Spinal Injury Association Impairment Scale (AIS) grading (A, B, C, D, E), and time since injury (months). Participants were also categorized as to whether or not they were taking at least one neuroactive drug at the moment of the cognitive evaluation (Yes/No).

\section{Neuropsychological assessment}

A comprehensive motor-free battery of neuropsychological assessments that were considered reliable and reproducible measures of attention, concentration, memory, abstract reasoning, and problem-solving ability was given to all participants. The total time required to complete the battery was less than $1.5 \mathrm{~h}$ for all participants. A first neuropsychological screening was done using an MMSE [23], and only individuals with a score of 22 or more underwent further evaluation. For the complete neuropsychological evaluation, a battery of commonly used neuropsychological tests was performed. All tests were administered and scored by a psychologist. The test battery included the following:

\section{Attention}

Digit Span Test subtest of the Wechsler Memory Scale III [24].

\section{Processing speed}

Mental Control test of the Wechsler Memory Scale -III [24]

Memory

Visual Memory test [25, 26,].

\section{Learning and memory}

Spain-Complutense Verbal Learning Test (TAVEC) for the evaluation of episodic verbal memory, which consists of a list of words that are presented to the subject five times with the purpose of evaluating different memory processes, such as immediate recall, learning curve, and information storage $20 \mathrm{~min}$ after the last presentation of the list. For verbal memory, the following variables were obtained from the TAVEC [27]: (1) Immediate recall on the first trial with verbal material (RIA1) and 5 min later (RIA5); (2) Total immediate recall with verbal material (RIAT); (3) Shortterm free recall with verbal material (RLCP); (4) Long-term free recall with verbal material (RLLP); (5) Recognition with verbal material (RCN); (6) Short-term semantic recall with verbal material (Semantic RLCP); (7) Long-term semantic recall with verbal material (Semantic RLLP); (8) Short-term serial recall with verbal material (Serial RLCP); (9) Long-term serial recall with verbal material (Serial RLLP); (10) Semantic clustering in free recall (Semantic RIA1); (11) Serial clustering in free recall (Serial RIA1); (12) RCl-CP (Short-delay cued recall); (13) RCl-LP (Longdelay cued recall).

\section{Executive Functions and recognition}

The following TAVEC [27] variables were obtained: (1) Repetitions on the same trial (Perseveration); (2) Free recall intrusions, any word not in the appropriate list or category (IRL); (3) Cued recall intrusions (IRCl); (4) Discriminability (ability to identify correct words (hits) relative to the ability to reject wrong words (false positives); (5) Bias (the tendency to favor "yes" or "no" responses when they are doubtful about the correct answer); (6) False positives.

\section{Emotional status assessment}

It is well known that depression and anxiety may interfere with cognitive performance [16, 28,]. For this reason, we evaluated depression and anxiety using the Beck Depression Inventory (BDI) [29] and State Anxiety Inventory (STAI) [30]. The BDI contains 21 items that asses both the somatic and affective aspects of depression. While there is some indication that the BDI may inflate estimates in individuals with SCI because of some somatic-based items, 
it has been shown to be generally reliable with samples of people with SCI [31]. The STAI is widely used in assessing anxiety and has been used with samples of people with SCI $[16,32,33$,$] . The STAI explores both the anxious trait$ (STAI-T) and the anxious status (STAI-S). The BDI and STAI were added to this study to investigate the role of depression and anxiety in objective cognitive performance and self-report of cognition for individuals with SCI and trauma $[16,32,33$,].

\section{Data analysis}

The demographic and clinical characteristics of the groups were described by means and standard deviations or percentages, and compared by Student's $t$-tests for numerical variables (age, time since injury, BDI, STAI-T, STAI-S) and Pearson $\chi^{2}$, Fisher's exact, or likelihood ratio tests for categorical variables (sex, educational level, lesion level, and AIS).

The neuropsychological tests of the groups were described by means and standard deviations. The absolute difference between the groups (controls versus subacute, controls versus chronic, and subacute versus chronic), with their $95 \%$ confidence interval was calculated. We also calculated the standardized difference (Cohen's $D$ ), considering a small $(d \sim 0.20)$, medium ( $d \sim 0.50)$, large $(d \sim 0.80)$, and very large $(d \sim 1.30)$ effect size. Some neuropsychological variables (MMSE, Visual Memory, RIA5, and others) were significantly biased and their normalization was not achieved by logarithmic or other transformations, so it was not possible to use linear models (ANCOVA). For this reason, the statistical significance of the association between group and neuropsychological variable (adjusted $p$ value) was computed using generalized linear models with a logit link function. The model was constructed by entering the group as the dependent variable and the neuropsychological variable as independent, adjusting for covariates of gender, educational level, and BDI (see results). When the groups with subacute and chronic SCI were compared, the AIS also was used as a covariate (see results). The significance level was set at $p<0.05$. In order to be more sensitive than specific, we decided not to apply correction for multiple comparisons. We report the $p$ value and the adjusted $p$ value so the reader can judge the robustness of our results, together with the Cohen's $D$ effect size and the individual tests outside the adjusted normative range. Neuropsychological assessment was further evaluated and each individual value was compared with its reference range obtained from a matched control population. So, for each test, we obtained the number of individuals outside their reference range. A Pearson $\chi^{2}$ test or Fisher's exact test was used to compare the number of individuals outside the normal range of the two groups with SCI. Moreover, individual
Table 1 Demographic and clinical characteristics of controls and spinal cord injury subacute and chronic patients

\begin{tabular}{|c|c|c|c|c|}
\hline & $\begin{array}{l}\text { Controls } \\
N=27\end{array}$ & $\begin{array}{l}\text { Subacute } \\
N=32\end{array}$ & $\begin{array}{l}\text { Chronic } \\
N=34\end{array}$ & $p$-Value \\
\hline \multicolumn{5}{|c|}{ Age mean (M; SD) } \\
\hline & $44.9(15.5)$ & $44.4(15.7)$ & $46.6(12.2)$ & $0.529 *$ \\
\hline & & & & $0.919 * *$ \\
\hline & & & & $0.620 * * *$ \\
\hline \multicolumn{5}{|l|}{$\operatorname{Sex} n(\%)$} \\
\hline Male & $12(44.4 \%)$ & $23(71.9 \%)$ & $24(70.6 \%)$ & $0.908 *$ \\
\hline \multirow[t]{2}{*}{ Female } & $15(55.5 \%)$ & $9(28.1 \%)$ & $10(29.4 \%)$ & $\mathbf{0 . 0 3 3} * *$ \\
\hline & & & & $\mathbf{0 . 0 3 9} * * *$ \\
\hline \multicolumn{5}{|l|}{ Education $n(\%)$} \\
\hline Read/Write & $2(7.4 \%)$ & $3(9.4 \%)$ & $4(11.8 \%)$ & \\
\hline Primary & $5(18.5 \%)$ & $12(37.5 \%)$ & $17(50 \%)$ & $0.104 *$ \\
\hline Secondary & $11(40.7 \%)$ & $13(40.7 \%)$ & $8(23.6 \%)$ & $0.292 * *$ \\
\hline University & $9(33.3 \%)$ & $4(12.5 \%)$ & $5(14.7 \%)$ & $0.019 * * *$ \\
\hline \multicolumn{5}{|c|}{ Injury level $n(\%)$} \\
\hline Cervical & - & $16(50 \%)$ & $10(29.4 \%)$ & \\
\hline Dorsal & - & $13(40.6 \%)$ & $19(55.9 \%)$ & $0.229 *$ \\
\hline Lumbar & - & $3(7.4 \%)$ & $5(14.7 \%)$ & \\
\hline \multicolumn{5}{|l|}{ ASIA n (\%) } \\
\hline A & - & $9(28.1 \%)$ & $22(64.7 \%)$ & \\
\hline B & - & $6(18.8 \%)$ & $4(11.8 \%)$ & $0.014 *$ \\
\hline $\mathrm{C}$ & - & $8(25 \%)$ & $6(17.6 \%)$ & \\
\hline $\mathrm{D}$ & - & $9(28.1 \%)$ & $2(5.9 \%)$ & \\
\hline \multicolumn{5}{|l|}{ BDI } \\
\hline & $5.4(6.2)$ & $8.6(7.7)$ & $9.8(8.2)$ & $0.54 *$ \\
\hline & & & & $\begin{array}{l}0.10 * * \\
0.035 * * *\end{array}$ \\
\hline
\end{tabular}

STAI-

$$
\begin{array}{lll}
18.5(9.6) \quad 22.4(13.2) \quad 19.2(0.4) \quad & 0.34 * \\
& & 0.21^{* *} \\
& & 0.80^{* * *}
\end{array}
$$

STAI-S

$\begin{array}{lll}18.4(9.9) \quad 20.6(11.4) \quad 22.9(13.5) & 0.49 \\ & & 0.37^{* *} \\ & 0.13^{* * *}\end{array}$

Time since injury (months) mean (M; SD)

\begin{tabular}{llll}
- & $5.9(1.9)$ & 137.3 & $<\mathbf{0 . 0 0 1} *$ \\
& $(104.6)$ & \\
\hline
\end{tabular}

$S D$ standard deviation

*Subacute/chronic

**Controls/subacute

***Control/chronic patients

participants were stratified into two groups: (1) people with 3 or fewer neuropsychological test results outside normal limits, and (2) people with more than 3 neuropsychological test results outside normal limit. A Pearson $\chi^{2}$ test was used to compare the number of individuals with $\leq 3$ or $>3$ tests outside the normal limit in the two groups with SCI 
Table 2 Comparison of the raw scores of neuropsychological assessment of subacute spinal cord injury patients and controls

\begin{tabular}{|c|c|c|c|c|c|c|c|c|}
\hline \multirow[t]{2}{*}{ Neuropsychological test } & \multicolumn{2}{|c|}{$\begin{array}{l}\text { Mean raw scores (standard } \\
\text { deviations) }\end{array}$} & \multirow[t]{2}{*}{$\begin{array}{l}\text { Mean } \\
\text { difference }\end{array}$} & \multicolumn{2}{|c|}{$95 \% \mathrm{CI}$ of difference } & \multicolumn{2}{|c|}{ Cohen's $D p$-Value } & \multirow[t]{2}{*}{$p^{\mathrm{a}-\text { Value* }}$} \\
\hline & $\begin{array}{l}\text { Controls } \\
N=27\end{array}$ & $\begin{array}{l}\text { Subacute } \\
N=32\end{array}$ & & $\begin{array}{l}\text { Lower } \\
\text { limit }\end{array}$ & $\begin{array}{l}\text { Upper } \\
\text { limit }\end{array}$ & $\bar{d}$ & $p$ & \\
\hline MMSE & $27.9(0.3)$ & $27.2(1.2)$ & 0.7 & 0.3 & 1.2 & 0.888 & 0.01 & 0.023 \\
\hline Digit span total & $22.0(4.2)$ & $15.8(3.8)$ & 6.2 & 4.1 & 8.3 & 1.557 & $<0.001$ & $<0.001$ \\
\hline Mental control & $32.8(6.3)$ & $23.9(7.5)$ & 8.9 & 5.3 & 12.5 & 1.28 & $<0.001$ & 0.005 \\
\hline Visual memory & $9.1(1.3)$ & $7.8(1.7)$ & 1.3 & 0.5 & 2 & 0.857 & 0.006 & 0.035 \\
\hline \multicolumn{9}{|l|}{ LEARNING AND MEMORY } \\
\hline RIA1 (List A trial 1) & $7.7(2.6)$ & $5.3(1.6)$ & 2.4 & 1.3 & 3.6 & 1.166 & 0.001 & 0.004 \\
\hline RIA5 (List A trial 5) & $14.5(2.1)$ & $12.9(2.8)$ & 1.6 & 0.3 & 2.8 & 0.645 & 0.027 & 0.399 \\
\hline RIAT (List A total 1-5) & $60.3(11.0)$ & $50.5(11.5)$ & 9.8 & 4 & 15.7 & 0.869 & 0.004 & 0.055 \\
\hline RLCP (Short-delay free recall) & $12.2(3.3)$ & $11.3(3.3)$ & 0.9 & -0.1 & 3.3 & 0.273 & 0.07 & 0.604 \\
\hline RLLP (Long-delay free recall) & $13.6(2.8)$ & $11.7(2.9)$ & 1.9 & 0.5 & 3.5 & 0.666 & 0.016 & 0.211 \\
\hline RCN (Recognition hits) & $15.6(0.8)$ & $14.9(1.1)$ & 0.7 & 0.2 & 1.2 & 0.727 & 0.016 & 0.127 \\
\hline \multicolumn{9}{|l|}{ Recall } \\
\hline Semantic RLCP & $7.8(3.8)$ & $4.5(3.2)$ & 3.3 & 1.5 & 5.2 & 0.95 & 0.001 & 0.021 \\
\hline Semantic RLLP & $8.5(4.0)$ & $5.6(3.3)$ & 2.9 & 1 & 4.9 & 0.801 & 0.005 & 0.056 \\
\hline Serial RLCP & $0.5(1.1)$ & $0.9(1.2)$ & -0.4 & -1 & 0.2 & -0.364 & 0.166 & 0.428 \\
\hline Serial RLLP & $0.1(0.3)$ & $0.9(1.1)$ & -0.8 & -1.2 & -0.4 & -1.09 & 0.007 & 0.009 \\
\hline \multicolumn{9}{|l|}{ Encoding } \\
\hline Semantic RIA1 & $27.4(14.6)$ & $14.7(8.9)$ & 12.7 & 6.1 & 19.1 & 1.104 & 0.001 & 0.012 \\
\hline Serial RIA1 & $3.2(2.4)$ & $5.5(4.5)$ & -2.3 & -4.1 & -0.4 & -0.65 & 0.028 & 0.02 \\
\hline RCl-CP (Short-delay cued recall) & $13.7(2.6)$ & $11.9(3.3)$ & 1.8 & 0.3 & 3.4 & 0.604 & 0.028 & 0.235 \\
\hline RCl-LP (Long-delay cued recall) & $14.2(2.4)$ & $12.2(2.7)$ & 2 & 0.7 & 3.4 & 0.78 & 0.007 & 0.055 \\
\hline \multicolumn{9}{|l|}{ EXECUTIVE FUNCTIONS } \\
\hline Perseveration & $0.8(1.5)$ & $2.7(2.1)$ & -1.9 & -2.8 & 0.9 & -1.041 & 0.003 & 0.003 \\
\hline \multicolumn{9}{|l|}{ Intrusion } \\
\hline IRL (Free recall intrusions) & $1.4(2.4)$ & $2.8(2.9)$ & -1.4 & -2.8 & 0 & -0.524 & 0.06 & 0.040 \\
\hline IRCl (Cued recall intrusions) & $0.4(0.8)$ & $1.6(2.0)$ & -1.2 & -1.9 & -0.5 & -0.827 & 0.017 & 0.025 \\
\hline \multicolumn{9}{|l|}{ RECOGNITION } \\
\hline Discriminability & $97.5(2.9)$ & $94.6(4.6)$ & 2.9 & 0.9 & 4.8 & 0.759 & 0.014 & 0.115 \\
\hline Bias & $0.0(0.2)$ & $0.0(0.4)$ & 0 & 0 & 0.1 & -0.04 & 0.87 & 0.745 \\
\hline False positive & $0.3(0.7)$ & $1.5(1.8)$ & -1.2 & -1.8 & -0.5 & -0.925 & 0.012 & 0.038 \\
\hline
\end{tabular}

$p^{\mathrm{a}^{*}}: p$ adjusted for gender, education, and BDI

Bold: $p^{\mathrm{a}}<0.05$ and $d>0.8$

(subacute and chronic). All analyses were performed using IBM SPSS for Windows, version 23.0 (Armonk, NY: IBM Corp).

\section{Results}

Characteristics of the 66 participants with SCI (32 subacute and 34 chronic) are summarized in Table 1, which shows that there were no significant differences between participants with respect to age, sex, educational level, and lesion level. AIS was significantly different in both samples $\left(X^{2}=\right.$
$10.5 p=0.014$ ) with motor complete participants (AIS A) more represented in the chronic group $(n=22)$ than in subacute group $(n=9)$ and AIS D more represented in the subacute group $(n=9)$ than in chronic group $(n=2)$. Time since injury was obviously longer in the chronic than in subacute SCI group (unpaired $t=-7.32, p<0.001$ ). In the group with subacute SCI, $93.7 \%$ of participants were taking at least one neuroactive drug while this percentage was $73.5 \%$, in the group with chronic SCI (Mann-Whitney, $p=$ 0.029). In the control group, more females were recruited compared to both groups with SCI. No participants were excluded based on the MMSE screening. 
Table 3 Comparison of the raw scores of neuropsychological assessment of chronic spinal cord injury patients and controls

\begin{tabular}{|c|c|c|c|c|c|c|c|c|}
\hline \multirow[t]{2}{*}{ Neuropsychological test } & \multicolumn{2}{|c|}{$\begin{array}{l}\text { Mean raw scores (standard } \\
\text { deviations) }\end{array}$} & \multirow[t]{2}{*}{$\begin{array}{l}\text { Mean } \\
\text { difference }\end{array}$} & \multicolumn{2}{|c|}{$95 \% \mathrm{CI}$ of difference } & \multirow[t]{2}{*}{ Cohen's $D$} & \multirow[t]{2}{*}{$p$-Value } & \multirow[t]{2}{*}{$p^{\mathrm{a}-\text { Value }}$} \\
\hline & $\begin{array}{l}\text { Controls } \\
N=27\end{array}$ & $\begin{array}{l}\text { Chronic } \\
N=34\end{array}$ & & $\begin{array}{l}\text { Lower } \\
\text { limit }\end{array}$ & $\begin{array}{l}\text { Upper } \\
\text { limit }\end{array}$ & & & \\
\hline MMSE & $27.9(0.3)$ & $26.8(1.7)$ & 1.1 & 0.5 & 1.7 & 1.018 & 0.015 & 0.012 \\
\hline Digit span total & $22.0(4.2)$ & $14.5(4.9)$ & 7.5 & 5.2 & 9.8 & 1.634 & $<0.001$ & 0.001 \\
\hline Mental control & $32.8(6.3)$ & $23.2(7.3)$ & 9.6 & 6 & 13 & 1.4 & $<0.001$ & 0.001 \\
\hline Visual memory & $9.1(1.3)$ & $7.1(2.1)$ & 2 & 1.1 & 2.8 & 1.146 & 0.001 & 0.011 \\
\hline \multicolumn{9}{|l|}{ LEARNING AND MEMORY } \\
\hline RIA1 (List A trial 1) & $7.7(2.6)$ & $4.1(1.9)$ & 3.6 & 2.4 & 4.8 & 1.629 & $<0.001$ & 0.001 \\
\hline RIA5 (List A trial 5) & $14.5(2.1)$ & $10.4(2.6)$ & 4.1 & 2.9 & 5.3 & 1.724 & $<0.001$ & $<0.001$ \\
\hline RIAT (List A total 1-5) & $60.3(11.0)$ & $39.7(9.9)$ & 20.6 & 15.1 & 26 & 1.983 & $<0.001$ & $<0.001$ \\
\hline RLCP (Short-delay free recall) & $12.9(3.3)$ & $8.2(3.1)$ & 4.7 & 3.1 & 6.4 & 1.474 & $<0.001$ & 0.001 \\
\hline RLLP (Long-delay free recall) & $13.6(2.8)$ & $8.6(3.5)$ & 5 & 3.5 & 6.7 & 1.567 & $<0.001$ & 0.001 \\
\hline RCN (Recognition hits) & $15.6(0.8)$ & $13.3(2.7)$ & 2.3 & 1.3 & 3.3 & 1.237 & 0.002 & 0.005 \\
\hline \multicolumn{9}{|l|}{ Recall } \\
\hline Semantic RLCP & $7.8(3.8)$ & $2.4(2.5)$ & 5.4 & 3.7 & 7.1 & 1.756 & $<0.001$ & 0.001 \\
\hline Semantic RLLP & $8.5(4.0)$ & $3.0(2.8)$ & 5.5 & 3.7 & 7.3 & 1.651 & $<0.001$ & 0.001 \\
\hline Serial RLCP & $0.5(1.1)$ & $0.6(0.7)$ & -0.1 & -0.6 & 0.4 & -0.114 & 0.64 & 0.815 \\
\hline Serial RLLP & $0.1(0.3)$ & $0.4(0.7)$ & -0.3 & -0.6 & -0.1 & -0.574 & 0.045 & 0.092 \\
\hline \multicolumn{9}{|l|}{ Encoding } \\
\hline Semantic RIA1 & $27.4(14.6)$ & $8.3(5.9)$ & 19 & 12.9 & 25.1 & 1.959 & $<0.001$ & 0.001 \\
\hline Serial RIA1 & $3.2(2.4)$ & $3.6(2.1)$ & -0.4 & -1.6 & 0.8 & -0.179 & 0.46 & 0.454 \\
\hline $\begin{array}{l}\mathrm{RCl}-\mathrm{CP} \text { (Short-delay cued } \\
\text { recall) }\end{array}$ & $13.7(2.6)$ & $8.7(3.3)$ & 5 & 3.5 & 6.5 & 1.672 & $<0.001$ & 0.001 \\
\hline $\begin{array}{l}\mathrm{RCl} \text {-LP (Long-delay cued } \\
\text { recall) }\end{array}$ & $14.2(2.4)$ & $8.8(3.6)$ & 5.4 & 3.9 & 7 & 1.76 & $<0.001$ & $<0.001$ \\
\hline \multicolumn{9}{|l|}{ EXECUTIVE FUNCTIONS } \\
\hline Perseveration & $0.8(1.5)$ & $3.3(3.9)$ & -2.5 & -3.9 & -0.9 & -0.881 & 0.01 & 0.034 \\
\hline \multicolumn{9}{|l|}{ Intrusions } \\
\hline IRL (Free recall intrusions) & $1.4(2.4)$ & $4.8(4.9)$ & -3.4 & -5.3 & -1.5 & -0.896 & 0.008 & 0.021 \\
\hline IRCl (Cued recall intrusions) & $0.4(0.8)$ & $3.3(3.2)$ & -2.9 & -4 & -1.7 & -1.357 & $<0.001$ & 0.001 \\
\hline \multicolumn{9}{|l|}{ RECOGNITION } \\
\hline Discriminability & $97.5(2.9)$ & $86.5(9.5)$ & 11 & 7.5 & 14.4 & 1.672 & $<0.001$ & 0.001 \\
\hline Bias & $0.0(0.2)$ & $0.0(0.4)$ & 0 & -0.2 & 0.1 & -0.118 & 0.68 & 0.3 \\
\hline False positives & $0.3(0.7)$ & $5.2(13.7)$ & -4.9 & -9.6 & -0.1 & -0.617 & 0.002 & 0.004 \\
\hline
\end{tabular}

$p^{\mathrm{a}^{*}}: p$ adjusted for gender, education, and BDI

Bold: $p^{\mathrm{a}}<0.05$ and $d>0.8$

Regarding emotional status, minimal differences were observed between the three groups. The most important difference was the tendency to more depressive mood found in those with subacute SCI and a significant depressive mood found in those with chronic SCI $(p=0.035)$ in comparison with the control group.

The comparison of the neuropsychological assessment between controls and those with subacute SCI showed altered cognitive function with a large or very large effect size between groups in the domain of attention, processing speed, memory and learning, executive functions (cued recall intrusions), and in recognition (false positive). A medium effect size was observed in encoding (Serial RIA1) and free recall intrusions. Data and statistics are reported in Table 2.

Comparison of the neuropsychological assessment between controls and those with chronic SCI showed altered cognitive function with a large or very large effect size between groups in the domain of attention, processing speed, memory, learning, executive functions (free and cued 
Table 4 Comparison of the raw scores of neuropsychological assessment of subacute and chronic spinal cord injury participants

\begin{tabular}{|c|c|c|c|c|c|c|c|c|}
\hline \multirow[t]{2}{*}{ Neuropsychological test } & \multicolumn{2}{|c|}{$\begin{array}{l}\text { Mean raw scores (standard } \\
\text { deviations) }\end{array}$} & \multirow[t]{2}{*}{$\begin{array}{l}\text { Mean } \\
\text { difference }\end{array}$} & \multicolumn{2}{|c|}{$95 \% \mathrm{CI}$ of difference } & \multicolumn{2}{|c|}{ Cohen's $D p$-Value } & \multirow[t]{2}{*}{$p^{\mathrm{a}-\text { Value* }}$} \\
\hline & $\begin{array}{l}\text { Subacute } \\
N=32\end{array}$ & $\begin{array}{l}\text { Chronic } \\
N=34\end{array}$ & & $\begin{array}{l}\text { Lower } \\
\text { limit }\end{array}$ & $\begin{array}{l}\text { Upper } \\
\text { limit }\end{array}$ & $\bar{d}$ & $p$ & \\
\hline MMSE & $27.2(1.2)$ & $26.8(1.7)$ & 0.4 & -0.3 & 1.1 & 0.274 & 0.289 & 0.341 \\
\hline Digit span total & $15.8(3.8)$ & $14.5(4.9)$ & 1.3 & -0.9 & 3.4 & 0.294 & 0.239 & 0.265 \\
\hline Mental control & $23.9(7.5)$ & $23.2(7.3)$ & 0.7 & -3 & 4.3 & 0.095 & 0.722 & 0.722 \\
\hline Visual memory & $7.8(1.7)$ & $7.1(2.1)$ & 0.7 & -0.2 & 1.6 & 0.367 & 0.151 & 0.09 \\
\hline \multicolumn{9}{|l|}{ LEARNING AND MEMORY } \\
\hline RIA1 (List A trial 1) & $5.3(1.6)$ & $4.1(1.9)$ & 1.2 & 0.2 & 2 & 0.684 & 0.018 & 0.018 \\
\hline RIA5 (List A trial 5) & $12.9(2.8)$ & $10.4(2.6)$ & 2.8 & 1.2 & 3.9 & 1.06 & 0.001 & 0.001 \\
\hline RIAT (List A total 1-5) & $50.5(11.5)$ & $39.7(9.9)$ & 10.8 & 5.4 & 16 & 1.012 & 0.001 & 0.001 \\
\hline RLCP (Short-delay free recall) & $11.3(3.3)$ & $8.2(3.1)$ & 3.1 & 1.6 & 4.7 & 0.97 & 0.001 & 0.001 \\
\hline RLLP (Long-delay free recall) & $11.7(2.9)$ & $8.6(3.5)$ & 3.1 & 1.5 & 4.7 & 0.966 & 0.001 & 0.002 \\
\hline RCN (Recognition hits) & $14.9(1.1)$ & $13.3(2.7)$ & 1.6 & 0.5 & 2.6 & 0.831 & 0.01 & 0.011 \\
\hline \multicolumn{9}{|l|}{ Recall } \\
\hline Semantic RLCP & $4.5(3.2)$ & $2.4(2.5)$ & 2.1 & 0.6 & 3.4 & 0.74 & 0.011 & 0.019 \\
\hline Semantic RLLP & $5.6(3.3)$ & $3.0(2.8)$ & 2.6 & 1 & 4.1 & 0.855 & 0.004 & 0.007 \\
\hline Serial RLCP & $0.9(1.2)$ & $0.6(0.7)$ & 0.3 & -0.2 & 0.8 & 0.318 & 0.19 & 0.144 \\
\hline Serial RLLP & $0.9(1.1)$ & $0.4(0.7)$ & 0.5 & 0 & 0.9 & 0.559 & 0.054 & 0.095 \\
\hline \multicolumn{9}{|l|}{ Encoding } \\
\hline Semantic RIA1 & $14.7(8.9)$ & $8.3(5.9)$ & 6.4 & 2.6 & 10.2 & 0.87 & 0.004 & 0.003 \\
\hline Serial RIA1 & $5.5(4.5)$ & $3.6(2.2)$ & 1.9 & 0.1 & 3.6 & 0.573 & 0.049 & 0.079 \\
\hline RCl-CP (Short-delay cued recall) & $11.1(3.3)$ & $8.7(3.3)$ & 2.4 & 1.5 & 4.8 & 0.727 & 0.001 & 0.002 \\
\hline RCl-LP (Long-delay cued recall) & $12.2(2.7)$ & $8.7(3.6)$ & 3.5 & 1.8 & 5 & 1.106 & 0.001 & 0.002 \\
\hline \multicolumn{9}{|l|}{ EXECUTIVE FUNCTIONS } \\
\hline Perseveration & $2.7(2.1)$ & $3.3(3.9)$ & -0.6 & -2.1 & 1 & -0.198 & 0.46 & 0.629 \\
\hline \multicolumn{9}{|l|}{ Intrusion } \\
\hline IRL (Free recall intrusions) & $2.8(2.9)$ & $4.8(4.9)$ & -2 & -4 & 0 & -0.509 & 0.062 & 0.257 \\
\hline IRCl (Cued recall intrusions) & $1.6(2.0)$ & $3.3(3.2)$ & -1.7 & 0.6 & -2.9 & -0.649 & 0.026 & 0.113 \\
\hline \multicolumn{9}{|l|}{ RECOGNITION } \\
\hline Discriminability & $94.6(4.6)$ & $86.5(9.5)$ & 8.1 & 4.4 & 11.7 & 1.137 & 0.001 & 0.003 \\
\hline Bias & $0.0(0.4)$ & $0.0(0.4)$ & 0 & -0.2 & 0.2 & 0.06 & 0.81 & 0.951 \\
\hline False positive & $1.5(1.8)$ & $5.2(13.7)$ & -3.7 & -8.5 & 1.1 & -0.467 & 0.03 & 0.153 \\
\hline
\end{tabular}

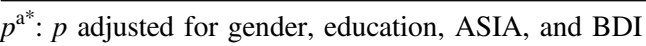

Bold: $p^{\mathrm{a}}<0.05$ and $d>0.6$

recall intrusions), and in recognition (discriminability). A medium effect size was observed in recognition (false positive). Data and statistics are reported in Table 3.

Comparison of the neuropsychological assessment between the two groups of people with SCI showed altered cognitive function (worsening respect to the subacute group with a medium or large effect size between groups) in the domain of memory, learning, and in recognition (discriminability). Data and statistics are reported in Table 4.

The prevalence of cognitive dysfunction in the chronic stage was also confirmed at the individual level (Table 5). Up to $50 \%$ of participants with chronic SCI presented more than 3 abnormal tests compared to approximately $20 \%$ of participants with subacute SCI $\left(X^{2}=5.9 ; p=0.014\right)$.

\section{Discussion}

Cognitive impairment in adults with SCI has been found to affect a large number of individuals (30-60\%) [5, 6, 8, 9,]. The risk of an adult with SCI having cognitive impairment is much higher than is found in the genearl population [18]. Moreover, cognitive impairment may influence the development of negative mood states [18]. We confirmed these 
Table 5 Individual neuropsychological alterations of spinal cord injury patients (number of patients with a given number of corrected tests outside normal limits)

\begin{tabular}{|c|c|c|c|}
\hline \multirow[t]{2}{*}{ Neuropsychological test } & \multicolumn{2}{|c|}{$\begin{array}{l}\text { Corrected tests outside } \\
\text { normal limits }\end{array}$} & \multirow[t]{2}{*}{$p$-Valu } \\
\hline & $\begin{array}{l}\text { Subacute } \\
N=32\end{array}$ & $\begin{array}{l}\text { Chronic } \\
N=34\end{array}$ & \\
\hline MMSE & $\begin{array}{l}\text { Exclusion } \\
\text { criteria }\end{array}$ & $\begin{array}{l}\text { Exclusion } \\
\text { criteria }\end{array}$ & \\
\hline Digit span total & $3 / 32$ & $8 / 34$ & 0.12 \\
\hline Mental control & $10 / 32$ & $7 / 34$ & 0.32 \\
\hline Visual memory & $17 / 32$ & $17 / 34$ & 0.80 \\
\hline \multicolumn{4}{|l|}{ LEARNING AND MEMORY } \\
\hline RIA1 (List A trial 1) & $7 / 32$ & $19 / 34$ & 0.005 \\
\hline RIA5 (List A trial 5) & $2 / 32$ & $12 / 34$ & 0.004 \\
\hline RIAT (List A total 1-5) & $5 / 32$ & $13 / 34$ & $\mathbf{0 . 0 3 9}$ \\
\hline RLCP (Short-delay free recall) & $2 / 32$ & $12 / 34$ & 0.004 \\
\hline RLLP (Long-delay free recall) & $1 / 32$ & $12 / 34$ & 0.001 \\
\hline RCN (Recognition hits) & $2 / 32$ & $10 / 34$ & 0.015 \\
\hline \multicolumn{4}{|l|}{ Recall } \\
\hline Semantic RLCP & $0 / 32$ & $2 / 34$ & 0.49 \\
\hline Semantic RLLP & $1 / 32$ & $6 / 34$ & 0.106 \\
\hline Serial RLCP & $1 / 32$ & $0 / 34$ & 0.48 \\
\hline Serial RLLP & $0 / 32$ & $0 / 34$ & - \\
\hline \multicolumn{4}{|l|}{ Encoding } \\
\hline Semantic RIA1 & $0 / 32$ & $3 / 34$ & 0.24 \\
\hline Serial RIA1 & $0 / 32$ & $2 / 34$ & 0.49 \\
\hline $\mathrm{RCl}-\mathrm{CP}$ (Short-delay cued recall) & $6 / 32$ & $17 / 34$ & 0.008 \\
\hline RCl-LP (Long-delay cued recall) & $5 / 32$ & $17 / 34$ & 0.003 \\
\hline \multicolumn{4}{|l|}{ EXECUTIVE FUNCTIONS } \\
\hline Perseveration Intrusion & $0 / 32$ & $2 / 34$ & 0.49 \\
\hline IRL (Free recall intrusions) & $3 / 32$ & $7 / 34$ & 0.20 \\
\hline IRCl (Cued recall intrusions) & $3 / 32$ & $6 / 34$ & 0.48 \\
\hline \multicolumn{4}{|l|}{ RECOGNITION } \\
\hline Discrimination & $3 / 32$ & $14 / 34$ & 0.003 \\
\hline Bias & $2 / 32$ & $6 / 34$ & 0.26 \\
\hline False positive & $5 / 32$ & $9 / 34$ & 0.281 \\
\hline$N$ of tests outside normal limits & $\begin{array}{l}\text { Subacute } \\
N=32\end{array}$ & $\begin{array}{l}\text { Chronic } \\
N=34\end{array}$ & \\
\hline$\leq \mathbf{3}$ & $26 / 32$ & $18 / 34$ & 0.014 \\
\hline$>\mathbf{3}$ & $6 / 32$ & $16 / 34$ & \\
\hline
\end{tabular}

Bold: $p<0.05$

findings both in individuals with subacute and chronic SCI. Altogether, our findings suggest that people with SCI present impairment in the domain of attention, processing speed, memory, learning, executive functions and recognition in the subacute stage that are still presents in the chronic stage. Most of these differences show large or very large size effects. Moreover, some cognitive functions, impaired in the group with subacute SCI, worsen in those with chronic SCI (see Table 4). No impaired cognitive functions in the subacute stage were better in the chronic stage.

The prevalence of cognitive dysfunction in the chronic stage was also confirmed at the individual level. Our data show, for the first time, that cognitive impairment is more severe and frequent in the chronic stage than in the subacute stage. In the memory domain, the alteration may suggest a deficit in the semantic strategy of recognition and encoding (this strategy is worst in those with chronic SCI than in those with subacute $\mathrm{SCI}$ ). We did not find any cognitive impairment that was present only in the subacute stage of the SCI. Most of the altered cognitive functions were impaired in the subacute stage and worsen with time. The emotional status was similar in both groups. Depressive mood levels were slightly higher in this SCI sample. This finding is apparently in contrast with previous literature, as higher depressive mood would be expected in SCI population [16]. On the other hand, we have to consider that our participants with SCI were unselected and were taking antidepressant drugs (if required) and with psychological support (if required). It is well known that depression may affect cognitive performance, so we cannot discard the possibility that it has some effects on the cognitive function of the sample with SCI presented here. On the other hand, depressive mood was similarly present in both those with subacute and chronic SCI, thus depressive mood alone cannot explain the worsening of cognitive function over time.

Most of the study participants were taking neuroactive drugs to treat depression, spasticity, and pain. These drugs may affect cognitive function and could have a great $\operatorname{cog}$ nitive impact on people with SCI. It is difficult, if not impossible, to understand the real impact of drugs on cognitive impairment. As far as the acute drug effects, the number of participants in the group with subacute SCI taking neuroactive drugs was higher than the number in the group with chronic SCI, thus it is unlikely that regular medication use can explain worsening of cognitive function over time. On the other hand, we cannot rule out the chronic (continuous receptors stimulation and adaptation, intersubject variability of the absorption and of the neuroeffects, etc.) effects of drugs on cognitive impairment.

A possible study limitation is that the control group included more females than the groups with SCI and that the control group had slightly higher educational level. This may produce an overestimation of cognitive impairment in this sample of people with SCI. The fact that the individual scores (corrected for sex and education) showed very similar results suggests that this difference had no effects on our evaluation.

Another possible study limitation is that individuals in the chronic group had more severe AIS grades than those in the subacute group. Those in the chronic group were recruited as they were attending the hospital for annual 
follow-up. It is possible that we failed to recruit less severe individuals (e.g., ASIA D). From a cognitive point of view, this selection bias may produce an overestimation of $\operatorname{cog}$ nitive worsening in people with SCI over time. The fact that the individual scores (corrected for AIS) gave very similar results suggests that this difference had no or marginal effects on our evaluation.

Our findings confirm that cognitive dysfunction after SCI is progressive. Our data do not allow for a mechanistic explanation of the cognitive dysfunction and of the progression over time that can be due to several factors such as the cumulative effects of neuroactive drugs, brain inflammation, psychological factors, etc [18-20].

In summary, most of the cognitive dysfunctions are present in the subacute stage and worsen with time. From a clinical point of view, we confirmed the presence of cognitive dysfunction that may interfere with the first stage of rehabilitation that is the most intense and important one. Moreover, the cognitive dysfunction may be important beyond the end of the first stage of rehabilitation as it can affect an individual's quality of life and possible reintegration to society.

Acknowledgements The friendly co-operation of participants is gratefully acknowledged.

\section{Compliance with ethical standards}

Conflict of interest The authors declare that they have no conflict of interest.

\section{References}

1. Wijesuriya N, Tran Y, Middleton J, Craig A. Impact of fatigue on the health-related quality of life in persons with spinal cord injury. Arch Phys Med Rehabil. 2012;93:319-24.

2. Pollard C, Kennedy P. A longitudinal analysis of emotional impact, coping strategies and post-traumatic psychological growth following spinal cord injury: a 10-year review. Br J Health Psychol. 2007;12:347-62.

3. Craig A, Tran Y, Wijesuriya N, Middleton J. Fatigue and tiredness in people with spinal cord injury. J Psychosom Res. 2012;73:205-10.

4. Craig A, Nicholson Perry K, Guest R, Tran Y, Middleton J. Adjustment following chronic spinal cord injury: Determining factors that contribute to social participation. Br J Health Psychol. 2015;20:807-23.

5. Cotter I. Cognitive impairment following SCI: implications for rehabilitation. In: Psychological aspects associated with spinal cord injury rehabilitation. Craig A and Tran Y (eds). Nova Science Publishers, Inc.: New York, 2008:175-192.

6. Dowler RN, Harrington DL, Haaland KY, Swanda RM, Fee F, Fiedler K. Profiles of cognitive functioning in chronic spinal cord injury and the role of moderating variables. J Int Neuropsychol Soc. 1997;3:464-72.

7. Kurylo M, Temple RO, Elliott TR, Crawford D. Rey Auditory Verbal Learning Test (AVLT) performance in individuals with recent-onset spinal cord injury. Rehabil Psychol. 2001;46:247-61.
8. Richards JS, Brown L, Hagglund K, Bua G, Reeder K. Spinal cord injury and concomitant traumatic brain injury. Results of a longitudinal investigation. Am J Phys Med Rehabil. 1988;67:211-6.

9. Roth E, Davidoff G, Thomas P, Doljanac R, Dijkers M, Berent S, et al. A controlled study of neuropsychological deficits in acute spinal cord injury patients. Paraplegia. 1989;27:480-9.

10. Tolonen A, Turkka J, Salonen O, Ahoniemi E, Alaranta H. Traumatic brain injury is under-diagnosed in patients with spinal cord injury. J Rehabil Med. 2007;39:622-6.

11. Tun CG, Tun PA, Wingfield A. Cognitive function following long-term spinal cord injury. Rehabil Psychol. 1997;42:163.

12. Hess DW, Marwitz JH, Kreutzer JS. Neuropsychological impairments after spinal cord injury: a comparative study with mild traumatic brain injury. Rehabil Psychol. 2003;48:151.

13. Craig A, Nicholson Perry K, Guest R, Tran Y, Dezarnaulds A, Hales A, et al. Prospective study of the occurrence of psychological disorders and comorbidities after spinal cord injury. Arch Phys Med Rehabil. 2015;96:1426-34.

14. McDermott LM, Ebmeier KP. A meta-analysis of depression severity and cognitive function. J Affect Disord. 2009;119:1-8.

15. Williams R, Murray A. Prevalence of depression after spinal cord injury: a meta-analysis. Arch Phys Med Rehabil. 2015;96:133-40.

16. Kennedy P, Rogers BA. Anxiety and depression after spinal cord injury: a longitudinal analysis. Arch Phys Med Rehabil. 2000;81:932-7.

17. Craig A, Tran Y, Middleton J. Psychological morbidity and spinal cord injury: a systematic review. Spinal Cord. 2009;47:108-14.

18. Craig A, Guest R, Tran Y, Middleton J. Cognitive impairment and mood states after spinal cord injury. J Neurotrauma. 2017;34:1156-63.

19. Wu J, Zhao Z, Sabirzhanov B, Stoica BA, Kumar A, Luo T, et al. Spinal cord injury causes brain inflammation associated with cognitive and affective changes: role of cell cycle pathways. J Neurosci. 2014;34:10989-1006.

20. Craig A, Tran Y, Siddall P, Wijesuriya N, Lovas J, Bartrop R, et al. Developing a model of associations between chronic pain, depressive mood, chronic fatigue, and self-efficacy in people with spinal cord injury. J Pain. 2013;14:911-20.

21. Young ME, Rintala DH, Rossi CD, Hart KA, Fuhrer MJ. Alcohol and marijuana use in a community-based sample of persons with spinal cord injury. Arch Phys Med Rehabil. 1995;76:525-32.

22. Heinemann AW, Keen M, Donohue R, Schnoll S. Alcohol use by persons with recent spinal cord injury. Arch Phys Med Rehabil. 1988;69:619-24.

23. Wingfield A, Tun CG, Gomez PT, Tun PA. Preservation of cognitive function after long-term tetraplegia. Am J Phys Med Rehabil. 2003;82:547-55.

24. Wechsler D, ed. Escala de memoria de Wechsler-III. Madrid: TEA Ediciones, S.A.; 2004.

25. Peña-Casanova J. Normalidad, semiología y patología neuropsicológicas. Programa integrado de exploración neuropsicológica. Test Barcelona Revisado. 2nd ed. Barcelona: Masson; 2005.

26. Peña-Casanova J, Bertrán-Serra I, Manero RM, Jane A. Versión abreviada del Test de Barcelona (I): Subtest y perfiles normales. Neurologia. 1997;12:99-111.

27. Benedet MJ, Alejandre MA, eds. Test de Aprendizaje Verbal España-Complutense (Manual). Madrid: TEA Ediciones, S.A.; 1998.

28. Davidoff G, Roth E, Richards J. Cognitive deficits in spinal cord injury: epidemiology and outcome. Arch Phys Med Rehabil. 1992;73:275-84.

29. Sanz J, Perdigón AL, Vazquez C. Adaptación española del Inventario para la Depresión de Beck-II: Propiedades psicométricas en población general. Clínica Y Salud. $2003 ; 14: 249-80$. 
30. Engels AS, Heller W, Spielberg JM, Warren SL, Sutton BP, Banich MT, et al. Co-occurring anxiety influences patterns of brain activity in depression. Cogn Affect Behav Neurosci. 2010;10:141-56.

31. Judd FK, Brown DJ, Burrows GD. Depression, disease and disability: application to patients with traumatic spinal cord injury. Paraplegia. 1991;29:91-96.
32. Craig AR, Hancock KM, Dickson HG. A longitudinal investigation into anxiety and depression in the first 2 years following a spinal cord injury. Paraplegia. 1994;32:675-9.

33. Kennedy P, Rogers B. Reported quality of life of people with spinal cord injuries: a longitudinal analysis of the first 6 months post-discharge. Spinal Cord. 2000;38:498-503. 